\title{
Colistimethate sodium for the treatment of chronic pulmonary infection in cystic fibrosis: an evidence-based review of its place in therapy
}

This article was published in the following Dove Press journal:

Core Evidence

19 September 2014

Number of times this article has been viewed

\section{Cordula Koerner-Rettberg Manfred Ballmann}

Department of Pediatric Pneumology, University Children's Hospital of Ruhr University Bochum at St JosefHospital, Bochum, Germany
Correspondence: Manfred Ballmann DRK Kinderklinik Siegen, Wellersbergstr 60, 57072 Siegen, Germany

Tel +4927I2 345225

Fax +49 27I2 1955

Email manfred.ballmann@drkkinderklinik.de
Abstract: Chronic bacterial respiratory-tract infections are a major driving force in the pathogenesis of cystic fibrosis (CF) lung disease and promote chronic lung-function decline, destruction, and progression to respiratory failure at a premature age. Gram-negative bacteria colonizing the airways in CF are a major problem in CF therapy due to their tendency to develop a high degree of resistance to antibiotic agents over time. Pseudomonas aeruginosa is the dominating bacterial strain infecting the CF lung from early childhood on, and multiresistant strains frequently develop after years of therapy. Colistin has been used for treating pulmonary bacterial infections in CF for decades due to its very good Gram-negative activity. However, drawbacks include concerns regarding toxicity when being applied systemically, and the lack of approval for application by inhalation in the USA for many years. Other antibiotic substances for systemic use are available with good to excellent Gram-negative and anti-Pseudomonas activity, while there are only three substances approved for inhalation use in the treatment of chronic pulmonary infection with proven benefit in CF. The emergence of multiresistant strains leaving nearly no antibiotic substance as a treatment option, the limited number of antibiotics with high activity against $P$. aeruginosa, the concerns about increasing the risk of antibiotic resistance by continuous antibiotic therapy, the development of new drug formulations and drug-delivery devices, and, finally, the differing treatment strategies used in CF centers call for defining the place of this "old" drug, colistimethate, in today's CF therapy. This article reviews the available evidence to reflect on the place of colistimethate sodium in the therapy of chronic pulmonary infection in $\mathrm{CF}$.

Keywords: Pseudomonas aeruginosa, treatment, multiresistant strains, Gram-negative bacteria, colistin

Clinical impact summary for colistimethate sodium in the treatment of chronic pulmonary infection in cystic fibrosis

\begin{tabular}{|lll|}
\hline Outcome measure & Evidence & Implications \\
\hline $\begin{array}{l}\text { Disease-oriented } \\
\text { evidence }\end{array}$ & $\begin{array}{l}\text { Demonstrates efficacy for the } \\
\text { treatment of chronic pulmonary } \\
\text { Pseudomonas aeruginosa infection in CF } \\
\text { Other agents might have a bigger } \\
\text { effect on lung function } \\
\text { Shows efficacy for the intravenous } \\
\text { treatment of } P \text {. aeruginosa-related } \\
\text { pulmonary exacerbations }\end{array}$ & $\begin{array}{l}\text { May be used when other } \\
\text { agents lack sufficient clinical } \\
\text { response and/or are resistant }\end{array}$ \\
& Nephro-/neurotoxicity is a \\
& manageable risk
\end{tabular}

(Continued) 


\begin{tabular}{|c|c|c|}
\hline \multicolumn{3}{|l|}{ (Continued) } \\
\hline Outcome measure & Evidence & Implications \\
\hline \multirow[t]{3}{*}{$\begin{array}{l}\text { Patient-oriented } \\
\text { evidence }\end{array}$} & $\begin{array}{l}\text { Fewer randomized clinical trials exist } \\
\text { than for alternative drugs }\end{array}$ & $\begin{array}{l}\text { Careful monitoring for } \\
\text { potential adverse events is } \\
\text { mandatory }\end{array}$ \\
\hline & Lacking data on optimal dosing & $\begin{array}{l}\text { Dosing should be within } \\
\text { the range of actual } \\
\text { recommendations }\end{array}$ \\
\hline & $\begin{array}{l}\text { Dry-powder preparation available } \\
\text { with proven efficacy }\end{array}$ & $\begin{array}{l}\text { Treatment with optimized } \\
\text { patient ease is possible }\end{array}$ \\
\hline Economic evidence & $\begin{array}{l}\text { Within the range of the costs } \\
\text { of alternative drugs }\end{array}$ & Cost-effective \\
\hline
\end{tabular}

\section{Introduction}

Chronic pulmonary infection is a hallmark of cystic fibrosis (CF) disease. Lung damage due to chronic airway infection is still the main cause of morbidity and death in CF patients. ${ }^{1}$ Lung infection, concomitant inflammation, and structural damage are interrelated processes in CF. Therefore, the treatment of lung infection to reduce its impact on pulmonary health in CF is of foremost importance. Multiple strategies have been employed to postpone the time of chronic infection after initial colonization of the lower respiratory tract with Pseudomonas aeruginosa and to minimize the effects of infection once the chronic infection is established, having improved the median survival of CF patients to more than 40 years. $^{2}$

Regular microbiological surveillance measures have been implemented in routine CF care in order to detect infection/colonization as early as possible. Different treatment protocols with the aim of eradicating a colonizing pathogen have emerged..$^{3-8}$ However, the issue as to which eradication regimen is superior is still open and beyond the scope of this article.

The rationale behind treatment strategies for established, chronic bacterial pulmonary infection is to reduce bacterial load and maintain lung function, or, ideally, restore some of the lost lung function, while endeavoring to ensure the designed treatment has the best effect and fewest possible adverse events and long-term resistance problems. Antibiotic interventions are used in chronic maintenance therapy, repeated intermittent antibiotic treatments, and interventions at times of exacerbation.

While, at an early age, strains such as Staphylococcus aureus and Haemophilus influenzae are the predominant colonizing organisms in the $\mathrm{CF}$ respiratory tract, from adolescence on, $P$. aeruginosa gains major importance and reaches a prevalence of $80 \%$ in adult patients. ${ }^{2}$ Stenotrophomonas maltophilia, methicillin-resistant Staphylococcus aureus (MRSA), Achromobacter xylosoxidans, and Burkholderia species are other well-known but less common pathogenic microorganisms colonizing the CF lung. ${ }^{2}$

Due to its typical susceptibility pattern, there are only a limited number of antibiotic substances suitable for the treatment of $P$. aeruginosa, and they are - except for oral chinolones (eg, ciprofloxacin) - exclusively antibiotics for parenteral or inhalation administration. Antibiotic treatment via the inhalation route is sensible in CF pulmonary infection, because the infected lower conducting airways are easily accessed by aerosol or powder inhalation preparations, resulting in high drug concentrations on the mucous membrane and sputum, the relevant sites of infection. Further, inhalation therapy is suitable for treatment in the home setting, enabling the long-term continuous treatment of chronic pulmonary infection.

Colistin has been used systemically and by inhalation in P. aeruginosa-related CF therapy in Europe for decades. ${ }^{9}$ From the 1980s, inhaled tobramycin was also increasingly used for treatment of chronic $P$. aeruginosa pulmonary infection, with well-proven benefits by the end of the $1990 \mathrm{~s},{ }^{10,11}$ which led to the approval of tobramycin inhalation solution in chronic $P$. aeruginosa infection in CF by 2001 . Tobramycin had been used for a long time before as intravenous solution and off-label for inhalation. ${ }^{9,12,13}$

In recent years, as a consequence of multiresistant strains evolving, there has been a search for new antibiotic agents. Aerosolized aztreonam was approved in 2010, ${ }^{14-16}$ and some other "old" antibiotics are in the pipeline for inhalation application, ${ }^{17}$ but the available antibiotics with which to treat multiresistant Gram-negative bacteria still remain very limited. At present, the three antibiotics tobramycin, colistimethate sodium, and aztreonam lysine are the only ones approved for inhalation therapy, partly existing with different preparations (as inhalation solution and dry powder).

Therefore, the question arises about which treatment is best for the individual patient. Can a decision be made about recommending a treatment as first-line therapy for chronic P. aeruginosa infection in CF? What do recent comparative 
studies teach us? Possible factors to consider are the individual patient's lung function or severity of disease, their possible preference (in terms of substance and inhalation device), the strain's resistance pattern, and the patient's individual tolerance or risk profile concerning drug side effects. What is the place of colistin in combination or sequential therapies? For colistin, as a very "old" agent, are dosing issues sufficiently solved? What is the place of colistin in non-Pseudomonas Gram-negative chronic pulmonary infections in CF?

This review evaluates colistimethate sodium in terms of its place in therapy for chronic pulmonary infection in $\mathrm{CF}$.

\section{Methods}

Data for this review were obtained through literature searches of publications included in PubMed until December 2013, references cited in relevant articles, and the World Wide Web. The main search terms used in the PubMed search were "colistin", "polymyxin E", "colistimethate sodium", "cystic fibrosis", "chronic pulmonary infection", "exacerbation", "nephrotoxicity", "neurotoxicity", "efficacy", and "antibiotic treatment". Only English-language papers were included.

\section{Colistin: chemical structure, mechanism of action, and available formulations}

"Colistin" (polymyxin E) is a multicomponent polypeptide antibiotic composed of colistin A and B belonging to the polymyxin group. It consists of a cyclic heptapeptide joined to a tripeptide side-chain acylated at the amino terminus by a fatty acid (Figure 1). The amino acid components in the molecule of colistin are D-leucine, L-threonine,

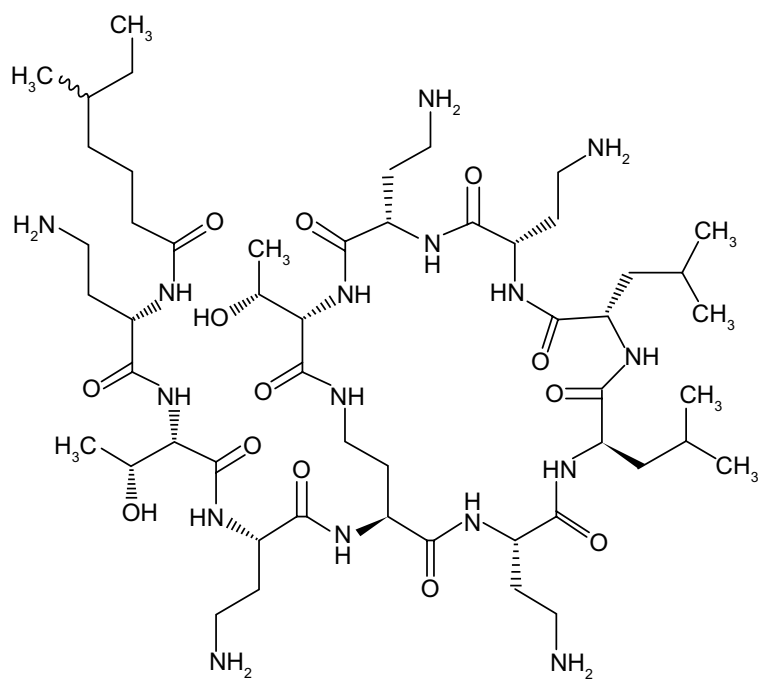

Figure I Chemical structure of colistin. and L- $\alpha$ - $\gamma$-diaminobutyric acid. Polymyxin B (another antimicrobial agent from the polymyxin group) has the same structure as colistin (polymyxin E) but contains D-phenylalanine instead of D-leucine, and is reported to cause more side effects, including bronchospasm, than colistin, ${ }^{18}$ therefore is not in use for inhalation.

Colistin has an antibacterial activity mainly against Gram-negative organisms. It is well known to have excellent activity against $P$. aeruginosa, but its spectrum of activity also comprises Escherichia coli, Enterobacter spp., Salmonella, Shigella, Klebsiella spp., and Acinetobacter baumannii, but Burkholderia spp., Serratia, and Proteus spp. are resistant. ${ }^{19}$

Colistin exists in two commercially available forms: colistin sulfate and colistimethate sodium. Colistin can be administered orally, topically, intramuscularly, intrathecally, intravenously, or by inhalation. As colistimethate sodium is the form with less toxicity and fewer side effects, it is the form administered systemically and by inhalation. It is converted in vivo to various derivatives, including the positively charged colistin base, which is the active form with antibacterial activity. Colistin acts on the bacterial cell membrane by binding to the LPS (lipopolysaccharide) component of the outer membrane of sensitive Gram-negative bacteria, increases cell permeability and leads to cell lysis and bacterial cell death. ${ }^{20}$ The antibacterial activity of colistin is concentration dependent (bacteriostatic in low concentrations and rapidly bactericidal in higher concentrations). At higher concentrations, a prolonged post-antibiotic effect can be observed. ${ }^{21,22}$ Because colistin uses its own uptake mechanism into the cell wall, it is not dependent on passive diffusion through porin channels, and is merely susceptible to the action of efflux pumps. Therefore, resistance against colistin develops quite rarely.

\section{History of colistimethate sodium use in CF therapy and other indications}

Colistin was initially discovered in Japan in 1947 from different species of Bacillus polymyxa, and was first used in 1959 for the treatment of multiresistant Gram-negative bacterial infections. Subsequently, it was quite frequently used during the 1960s and early 1970s, but toxicity (nephro- and neurotoxicity) was a serious issue, severely restricting the use of colistin after the early 1970s, when other antibiotic agents with good Gram-negative activity and a lower toxicity potential replaced it for systemic first-line therapy. ${ }^{23}$ In the past 15 years, the emergence of nosocomial infections - that is, 
ventilator-associated pneumonia, bacteremia, and other infections in intensive care due to multidrug-resistant Gramnegative bacteria - and the absence of new antibiotics against multiresistant Gram-negative strains have led to the revival of colistin as a salvage therapy for these indications. Recent studies suggest that colistin administered as monotherapy or in combination is an effective antimicrobial agent for multidrug-resistant Gram-negative bacterial infections has a safer profile than previously assumed. ${ }^{24}$ For these indications, colistin is now commonly administered intravenously. It is also used as an aerosol for ventilator-associated pneumonia treatment and intraventricularly/intrathecally for meningitis and ventriculitis treatment. ${ }^{25-27}$ However, randomized controlled trials assessing optimal benefit are missing and dosing issues are still under debate.

For many years, frequent systemic anti-Pseudomonas antibiotic treatment cycles have been one of the cornerstones of CF therapy. Colistin was used frequently for this purpose in the 1960s and early 1970s, since historically it is among the earliest substances used for $P$. aeruginosa treatment, due to its high activity against $P$. aeruginosa, even multiresistant strains. The mentioned toxicity concerns and the emergence of aminoglycosides and other antibiotics with strong anti-Pseudomonas activity then led to some decline in its use. However, from the late 1980s, colistin again came into frequent use in $\mathrm{CF}$, parenterally and by inhalation (especially in the UK), long before its revival outside of this indication. $^{28,29}$

The observation that the treatment effects of intravenous anti-Pseudomonas therapies decline within a few months of therapy called for additional strategies to control chronic infection between systemic treatment intervals. An inhalation therapy combines the advantage of achieving high concentrations in the respiratory tract while avoiding systemic side effects. Further, it has the advantage of being applicable in a safe and convenient way in a home setting. In the 1980s, antibiotic therapy via inhalation started to be employed in some small studies, using several different antibiotic substances including $\beta$-lactams, aminoglycosides, and colistin. ${ }^{30-32}$ Since no approved formulations for inhalation were available, intravenous drug formulations were used, and the selected doses resulted from the package size of the intravenous agent rather than from preclinical safety and efficacy testing. Whereas early studies showed serious deficits concerning power/sample size and study design, ${ }^{30}$ in the $1990 \mathrm{~s}$, inhaled tobramycin proved to be effective in treatment of chronic $P$. aeruginosa infection in the first welldesigned clinical studies of sufficient size. ${ }^{10,11}$ As data and experience with inhaled tobramycin accumulated, it evolved as first-line therapy for chronic $P$. aeruginosa colonization in many CF centers, ${ }^{33-35}$ and for many years it has been the only substance administered via inhalation in the USA, where aerosolized colistin lacks US Food and Drug Administration approval. This was different in Europe, from where much of the experience with colistin has come, as aerosolized colistin has been traditionally used in this part of the world for $P$. aeruginosa eradication and exacerbation therapies for decades, ${ }^{9}$ with approval in 1986 (Colomycin), and it is still in frequent use as a first- or second-line substance for the treatment of chronic suppressive $P$. aeruginosa depending on CF center policy.

\section{Efficacy of inhaled colistimethate sodium in CF patients with chronic pulmonary infection}

The first small study with colistin administered by inhalation in CF had an open, non-placebo-controlled design. ${ }^{36}$ A positive clinical effect (rate of sputum colonization) was demonstrated in CF patients in the setting of an early $P$. aeruginosa infection. This was well in line with other small controlled studies using other antibiotic agents such as gentamicin, carbenicillin, and amikacin via inhalation during the early 1980s. The first placebo-controlled study of colistin inhalation in CF patients with chronic $P$. aeruginosa lung infection was conducted by Jensen et al. ${ }^{28}$ In that prospective, double-blind, placebo-controlled clinical trial with consecutive randomization of chronically $P$. aeruginosainfected CF patients to active treatment and placebo arms, 40 patients aged 7 to 35 years were treated with 1 million units of colistimethate sodium or normal saline twice daily over 3 months. Before the start of the colistimethate sodium inhalation treatment, a 2-week intravenous treatment with tobramycin plus $\beta$-lactam antibiotics was administered. A treatment benefit (ie, superiority to placebo) in terms of clinical-symptoms score, maintenance of pulmonary function, and some inflammatory reaction was demonstrated, and the treatment was well-tolerated and caused no resistance problems. However, the effect on lung function was rather a reduction in lung function decline than a rise in lung function compared with the level of lung function at the start of the study. A strategy of inhalation colistin treatment as an adjunct to regular intravenous therapy has been proposed by the authors on the basis of this study. The same Copenhagen CF center compared patient outcome after early and aggressive repetitive colistin inhalation treatments (partly alongside oral ciprofloxacin) on every occasion $P$. aeruginosa was 
grown from the airways, with the historical patient outcome before colistin treatment was implemented. ${ }^{37} \mathrm{~A}$ benefit in the treatment group could be demonstrated, with not only the postponement of chronic $P$. aeruginosa infection but also an impact on lung function. A meta-analysis evaluating the different early studies on inhaled anti-Pseudomonas agents in CF therapy pointed out significant methodological shortcomings as far as study design and patient number are concerned. ${ }^{30}$ However, Mukhopadhyay et al concluded that the assumption can be made that treatment of chronic pulmonary CF lung infection by inhaled antibiotics, including colistin, is beneficial, as it improves lung function and reduces pulmonary exacerbations. This conclusion was shared by the authors of a review on all studies addressing this question published between 1965 and $1995 .{ }^{31}$ In that review, the authors found that most studies showed a reduction in hospital admissions and an improvement in lung function. No renal or ototoxicity was seen, and, while the induction of resistance to the used inhaled antibiotics was infrequent in the majority of the trials, it was up to $30 \%$ in some studies.

In the 1990s, two well-designed multicenter, randomized, placebo-controlled studies investigated the effect of tobramycin inhalation solution. ${ }^{10,11}$ In these trials, a marked effect of inhaled tobramycin could be demonstrated on lung function in terms of improvement in forced expiratory volume in 1 second (FEV1) from a pretreatment level of around 10\% during a 28 -day course, ${ }^{10}$ which persisted during a 24 -week period of on-off treatment cycles. ${ }^{11}$ Also, the exacerbation rate and $P$. aeruginosa sputum count decreased. Comparable effects on lung function were achieved in further studies using tobramycin inhalation solution. ${ }^{38-41}$

Large randomized controlled studies investigating colistin versus placebo are missing, and the effect on lung function versus placebo stated in the existing colistin trials was inferior to that demonstrated by inhaled tobramycin. However, concerns about increasing resistance rates by continuous antibiotic therapy and the availability of two substances for treatment of chronic P. aeruginosa infection with proven efficacy called for direct comparative studies of these agents. The first trial to directly compare nebulized tobramycin with colistin in a randomized controlled setting showed equal outcomes in terms of $P$. aeruginosa sputum density, resistance rates, and safety aspects. However, with tobramycin, a rise in lung function (FEV1 improvement of $6.7 \%$ from baseline, biggest effect in the pediatric/adolescent age group) was demonstrated after the 28-day treatment course, whereas, there was no significant effect on lung function with colistin. ${ }^{42}$ These results are in line with the already mentioned studies comparing these agents against placebo, and suggest that nebulized tobramycin is superior to colistin in the treatment of $\mathrm{CF}$ patients with chronic P. aeruginosa infection. However, there was a marked bias toward pretreatment of patients with inhaled colistin in the previous 6 months, with a very small number of patients having been treated with aerosolized tobramycin before. This may have influenced the outcome because of different susceptibilities toward the two agents and, possibly, different anticipations by the patients, as the study was not designed double blind. What is more, the colistin dose used was half that commonly used in adults. ${ }^{43}$ Yet a small open followup study ${ }^{44}$ of the study by Hodson et $\mathrm{al}^{42}$ with a treatment duration of a further 5 months confirmed the results of the shorter study, showing tobramycin to be superior to colistin in terms of its effect on lung function.

Recently, new powder preparations of the "old" antibiotics tobramycin and colistin have been developed to decrease the treatment burden by shortening the time for regular inhalation and increasing convenience in handling. Colistimethate sodium dry powder (Colobreathe DPI ${ }^{\circledR}$; Forest Laboratories UK Ltd, Dartford, UK ${ }^{45}$ was the second drug to be licensed for treatment of chronic P. aeruginosa pulmonary infection in CF in 2013 after tobramycin dry powder (Tobi ${ }^{\circledR}$ Podhaler ${ }^{\mathrm{TM}}$; Novartis Pharmaceuticals Corporation, East Hanover, NJ, USA) in $2011 .^{46,47}$ In the Freedom study, a multicenter, prospective, centrally randomized, Phase III open-label study, colistimethate sodium dry-powder formulation inhaled via the Turbospin ${ }^{\circledR}$ device (PH\&T SpA, Milan, Italy) was compared with classic tobramycin nebulizer solution..$^{45}$ The primary outcome measure was change in mean FEV1\% predicted from baseline after 24 weeks of treatment. Colistin was inhaled continuously over the duration of the study, whereas tobramycin was given on an on-off cycle basis according to the treatment regime applied in previous tobramycin Phase III regulatory trials. Importantly, all patients had to be treated with at least two 28-day cycles of tobramycin inhalation before randomization to either treatment arm, and the majority of patients had a history of pretreatment with aerosolized tobramycin for a median of 2 years. A total of 374 patients were included in the study (intention to treat); colistin was demonstrated to be non-inferior in terms of lung function throughout the 24 weeks of the study. This is in contrast to previous comparative studies in which colistin was found to be inferior to tobramycin; the reasons for this might be the relatively high dose of colistin (16,625 Mio IU) used twice daily in this study and the fact that the majority 
of patients in the colistin powder study had been pretreated with tobramycin for a long time (years) while possibly being naïve for colistin.

No significant difference in overall quality-of life score was shown between treatment groups, but the trial was not sufficiently powered to be able to detect this. In questionnaire items referring to treatment burden, colistin dry powder showed superiority to tobramycin solution inhalation, although treatment-related adverse events, such as cough, throat irritation, and abnormal taste, occurred significantly more frequently in the colistin dry-powder arm. The reduction in time necessary for inhalation will probably be the main reason for patients' weighing in favor of colistin dry powder. However, it has to be kept in mind that an inhalation device requiring longer inhalation times than devices frequently used for tobramycin solution in real life was used in the tobramycin arm.

In 2010, aztreonam lysine was approved as the third antibiotic substance for inhalation in CF chronic pulmonary infection. It was shown to be effective and safe compared with placebo ${ }^{14,15}$ and to produce a sustained improvement in lung function over a prolonged application ${ }^{16}$ and was superior to tobramycin solution inhalation in terms of the short-term effect on lung function during on-treatment cycles. ${ }^{48}$ However, in the latter trial, ${ }^{48}$ the majority of patients had been treated with inhaled tobramycin before, possibly accounting for the superiority of aztreonam lysine. No direct comparative study of aztreonam lysine to colistin exists as far as we are aware.

Since three different antibiotic agents, with two of them in different formulations, are approved for the treatment of chronic pulmonary infection in $\mathrm{CF}$ at this stage, the question arises as to which treatment should be used for which patient. A recent meta-analysis reviewing these five agents (colistimethate sodium and tobramycin both as inhalation solution and dry powder, and aztreonam lysine as inhalation solution) concluded that all substances have proven efficacy compared with placebo. ${ }^{49}$ Comparing these agents, tobramycin was regarded as superior to colistin inhalation solution in terms of the effect on lung function. However, colistin dry-powder solution was considered non-inferior to tobramycin inhalation solution. The tobramycin dry-powder preparation showed similar efficacy to the tobramycin aerosol preparation. finally, aztreonam lysine was regarded as superior to tobramycin in terms of short-term effect on lung function. The latest Cochrane review on this topic included 19 randomized controlled trials with control groups being either placebo or alternative antibiotic agents. ${ }^{50}$ It was concluded that while all agents available have a proven effect on lung function and exacerbation rate, which agent is superior cannot be reliably determined. Due to the number and size of studies, there is a bias for tobramycin as far as available evidence is concerned. The review by Ryan et $\mathrm{al}^{50}$ considered a true meta-analysis impossible, due to the significant variability in study design. Also, the meta-analysis by Máiz et $\mathrm{al}^{49} \mathrm{did}$ not aim to statistically control for important effect modifiers and differences in study design - for example, the rate of prior exposure of patients to active drugs, age, and baseline FEV1 level. Littlewood et al made an attempt to consider important confounders in their meta-analysis. ${ }^{51}$ They conducted a Bayesian network meta-analysis to combine the available randomized controlled trials in order to compare treatment effects that had not been compared in a head-to-head fashion before, and to account for the study heterogeneities of included trials. Eleven studies ${ }^{11,14-16,28,40-42,46,47,52}$ were included (Table 1), and different scenarios allowing for effects of covariates (ie, baseline age, baseline FEV1, or antibiotic pretreatment) were run. ${ }^{51}$ It was concluded that all available formulations (the two tobramycin inhalation solution formulations, tobramycin drypowder inhaler, aztreonam lysine, and colistimethate sodium inhalation solutions) have comparable efficacy, with a slight advantage of tobramycin over the others. Colistimethate dry powder inhalation (DPI) was not included in the study, since it was not yet on the market.

Table I Randomized controlled trials on inhaled antibiotics in patients with CF

\begin{tabular}{|c|c|c|c|}
\hline Source ${ }^{a}$ & Study type & $\begin{array}{l}\text { Duration } \\
\text { (weeks) }\end{array}$ & Treatments \\
\hline Konstan et $\mathrm{al}^{46}$ & $\mathrm{DB}, \mathrm{PC}, \mathrm{MC}$ & $\begin{array}{l}24 \text { (three } \\
4 \text {-week-cycles) }\end{array}$ & TIP vs Plac \\
\hline Konstan et $\mathrm{al}^{47}$ & OL, MC & $\begin{array}{l}24 \text { (three } \\
4 \text {-week-cycles) }\end{array}$ & TIP vs TIS-T \\
\hline Ramsey et al" & $\mathrm{DB}, \mathrm{PC}, \mathrm{MC}$ & $\begin{array}{l}24 \text { (three } \\
4 \text {-week-cycles) }\end{array}$ & TIS-T vs Plac \\
\hline Nasr et a $\left.\right|^{52}$ & $\mathrm{DB}, \mathrm{PC}$ & $\begin{array}{l}24 \text { (three } \\
4 \text {-week-cycles) }\end{array}$ & TIS-T vs Plac \\
\hline Hodson et $\mathrm{al}^{42}$ & OL, MC & 4 & TIS-T vs Col \\
\hline Jensen et $\mathrm{al}^{28}$ & $\mathrm{DB}, \mathrm{PC}$ & 13 & Col vs Plac \\
\hline Lenoir et $\mathrm{a}^{40}$ & $\begin{array}{l}\text { DB, PC, } \\
M C, P G\end{array}$ & $\begin{array}{l}8 \text { (one 4-week } \\
\text { cycle) }\end{array}$ & TIS-B vs Plac \\
\hline Chuchalin et $\mathrm{al}^{4 \mathrm{I}}$ & $\begin{array}{l}\mathrm{DB}, \mathrm{PC}, \\
\mathrm{MC}, \mathrm{PG}\end{array}$ & $\begin{array}{l}24 \text { (three } \\
4 \text {-week cycles) }\end{array}$ & TIS-B vs Plac \\
\hline McCoy et $\mathrm{al}^{14}$ & $\mathrm{DB}, \mathrm{PC}, \mathrm{MC}$ & $4+8$ follow-up & AZLI vs Plac \\
\hline Retsch-Bogart et al ${ }^{15}$ & $\mathrm{DB}, \mathrm{PC}, \mathrm{MC}$ & 4 & AZLI vs Plac \\
\hline Oermann et al ${ }^{16}$ & OL, PC, MC & $\begin{array}{l}24 \text { (three } \\
\text { 4-week cycles) }\end{array}$ & AZLI vs TIS-T \\
\hline Schuster et $\mathrm{a}^{45, \mathrm{~b}}$ & OL, MC & 24 & ColP vs TIS-T \\
\hline
\end{tabular}

Note: aStudies included in the network analysis by Littlewood et al, ${ }^{51}$ and ${ }^{b}$ one study not included.

Abbreviations: AZLI, aztreonam lysine inhalation solution; CF, cystic fibrosis; Col, colistimethate sodium inhalation solution; ColP, colistimethate sodium dry powder; DB, double blind; MC, multicenter; OL, open label; PC, placebo controlled; PG, parallel group; Plac, placebo; TIP, tobramycin dry powder; TIS-B, tobramycin inhalation solution (Bramitob ${ }^{\circledR}$ ); TIS-T, tobramycin inhalation solution (Tobi $\left.{ }^{\circledR}\right)$; vs, versus. 
In summary, at present, all available antibiotic drug formulations have been proven effective and are approved for the treatment of chronically colonized CF patients. A clear vote in favor of a specific agent cannot be provided at this time,${ }^{33-35}$ but tobramycin has at present the most comprehensive data on efficacy in chronic pulmonary infection in $\mathrm{CF}$. Forthcoming new drug formulations for inhalation use will necessitate an ongoing appraisal of this topic. ${ }^{53}$

\section{Use of inhaled colistin in combination or sequential therapy strategies together with other substances Sequential therapy}

The rationale behind the different evolving strategies that combine two or more antibiotics to treat chronic P. aeruginosa infection in CF is fed by several issues. First, there is the hope of minimizing the development of resistance against major P. aeruginosa active substances. Further, the decline in lung function during the off-phases in tobramycin maintenance therapy might be prevented by treating with colistin in those intervals. Finally, the reduced susceptibility of biofilms to antibiotics is thought to be due to their complex composition and the large heterogeneity in physiological states of bacterial cells within a biofilm, rendering many of its bacteria relatively unsusceptible to antibiotics. Hence, it is already the practice in many CF centers to employ sequential antibiotic treatment regimes with alternate use of inhaled tobramycin and colistin or other combinations for $P$. aeruginosa suppressive therapy, although clinical trials examining efficacy, resistance pattern, and safety are lacking.

\section{Combination therapy}

In an in vitro pilot study, the combination of ciprofloxacin and colistin has yielded promising results in killing $P$. aeruginosa biofilms based on the novel concept of combining antibiotics that target the different metabolic states of the biofilm cells. Bacteria with low metabolic activity were killed by colistin, whereas ciprofloxacin was found to specifically kill the subpopulation of metabolically active biofilm cells. ${ }^{54}$ Subsequently, another pilot study investigated the efficacy of the combination of tobramycin and colistin to kill P. aeruginosa biofilms. ${ }^{55}$ In that study, in two different in vitro biofilm models and in a rat lung-infection model, it was demonstrated that colistin-tobramycin combinations are superior to the single antibiotics for killing $P$. aeruginosa biofilm cells, resulting in reduced mortality rates and lung pathologic findings in the rat model. Further, it was shown that the combination of inhaled colistin and tobramycin is well tolerated in patients with $\mathrm{CF}$ and results in a significant decrease in $P$. aeruginosa colonyforming units in sputum specimens. ${ }^{55}$ These results suggest that simultaneous antibiotic combination therapy is more effective than treating with alternating single antibiotics to defeat lung disease in patients with $\mathrm{CF}$.

However, the superiority of a new long-term treatment to another regime has to be tested using relevant clinical outcome parameters. In previous efficacy trials, these have been lung-function parameters (ie, FEV1 increase, rate of FEV1 decline) and quality of life. However, instead, the true benefit from a combination or sequential antibiotic therapy might be a delay in the time at which a patient becomes refractory to the available inhaled antibiotic drugs, and this benefit could exist even if no differences in classical endpoints are detected over a limited study period. ${ }^{56}$ Thus, there is a need for alternative strategies to detect such possible benefits - for example, cautiously conducted withdrawal studies.

\section{Resistance rates to colistin compared with other antibiotics}

Chronic pulmonary $P$. aeruginosa infection in CF requires lifelong $P$. aeruginosa suppressive therapy. Therefore, the risk of developing resistance to the commonly used antibiotics is a relevant concern and may influence antibiotic treatment strategies.

Although $P$. aeruginosa resistance is usually low in non-CF patients, ${ }^{57}$ the emergence of multidrug-resistant Gram-negative bacteria, including $P$. aeruginosa, reduces treatment options - that is, in the setting of intensive care units (ICUs) ${ }^{58}$ - and leads to an increase in the use of colistin as salvage therapy. ${ }^{59}$ For CF, $P$. aeruginosa resistance is occurring even more frequently ${ }^{60}$ due to the long-term adaptation of bacterial strains in the individual's lung. Several surveys have examined the susceptibility patterns of P. aeruginosa isolated from CF patients. ${ }^{61-65}$ Resistance rates have been demonstrated to be quite high for some antibiotics commonly used for P. aeruginosa treatment, but still very low for colistin..$^{63,64,66}$ Reasons for the rare occurrence of colistin resistance might be the fact that colistin self-promotes its penetration of the cell envelope and causes irreversible disruption of the cytoplasmic membrane, and, further, that P. aeruginosa cannot modify the lipid A target of its LPS, where colistin binds to.

However, it is debatable whether treatment decisions should be made according to in vitro susceptibility testing, since inhaled antibiotics will often be effective in spite of 
in vitro resistance results, ${ }^{39,42,67}$ probably due to antibiotic concentrations much higher than the minimum inhibitory concentration achievable in sputum with inhalation use. Accordingly, in vitro antibiotic susceptibility results have not yet proven to be predictive of clinical response to inhaled antibiotics. Also, for intravenous use in the treatment of pulmonary exacerbations, antibiotic susceptibility testing is of questionable value, ${ }^{68}$ as is routine combination antimicrobial susceptibility testing. ${ }^{69,70}$ Therefore, treatment should be guided mainly according to clinical response.

\section{Use of colistimethate sodium for treatment of exacerbations in chronic pulmonary disease in CF}

Acute pulmonary exacerbations occur frequently in $\mathrm{CF}$ and are associated with progressive morbidity and mortality. Approximately $25 \%$ of CF patients will not regain their lung function after a pulmonary exacerbation, pointing to the necessity for the optimal and aggressive treatment of these events. ${ }^{71-73}$ A recent Cochrane meta-analysis could not find sufficient evidence concerning the effectiveness of inhaled antibiotics for the treatment of pulmonary exacerbations in $\mathrm{CF}^{74}$ Although data on intravenous antibiotic combination treatment are limited, current guidelines on treatment of pulmonary exacerbations in CF recommend the use of two intravenous antibiotics with different mechanisms of action in order to reduce resistance and optimize antibacterial activity. ${ }^{75-77}$ However, data on the ability of these combinations to prevent the development of resistance are limited. The treatment most frequently used by CF centers is the combination of a $\beta$-lactam and an aminoglycoside agent. ${ }^{78}$ However, the existence of multiresistant $P$. aeruginosa strains and insufficient treatment responses to antibiotic regimes calls for alternative treatment strategies. Intravenous colistimethate sodium is a treatment option since resistance to colistin is rare. It has been shown to be an effective treatment in $P$. aeruginosa-driven pulmonary exacerbations in three efficacy studies ${ }^{29,79,80}$ (also see review by Young et $\mathrm{al}^{81}$ ), with a better efficacy when combined with a second antibiotic agent. ${ }^{29}$ This is well in line with recommendations for the current standard therapy of using combination therapies in $\mathrm{CF}$ pulmonary exacerbations.

However, toxicity concerns are a relevant issue in systemic colistimethate therapy, hence a detailed reflection is reasonable.

\section{Toxicity issues}

Intravenous colistimethate sodium therapy has been reluctantly used for many years because of concerns related to toxicity, namely the well-reported nephro- and neurotoxicity. Studies addressing the incidence of nephrotoxicity in the earlier literature report acute tubular necrosis, prolonged increase of blood urea nitrogen levels, a fall in creatinine clearance, or other signs of impaired renal function, occurring in up to $50 \%$ of patients treated intravenously or intramuscularly (see Falagas et al for a comprehensive review of the earlier literature on colistin toxicity ${ }^{24}$ ).

However, in contrast to the earlier studies, more recent studies have shown that the incidence of nephrotoxicity is less common and less severe, affecting about $14 \%$ to $24 \%$ of patients in an ICU setting $23,26,58,82-84$ (see Falagas et al ${ }^{24}$ for a review of the various non-CF studies). A retrospective cohort study ${ }^{82}$ comparing the safety and efficacy of colistimethate sodium and tobramycin for treatment of multiresistant A. baumannii infections in ICU patients found that the risks of nephrotoxicity were similar. In another study comprising a higher number of cases, the nephrotoxic damage due to intravenous colistin therapy was reversible. ${ }^{85}$ The nephrotoxicity risk appeared to be related to the total cumulative dose of colistin. This indicates the need to carefully monitor kidney function in patients requiring prolonged therapy with colistimethate sodium and to avoid prolonged treatment courses whenever possible.

The avoidance of concurrent administration of other nephrotoxic drugs, different dosing regimes, as well as the more meticulous management of fluid and electrolyte abnormalities and use of more advanced critical care services, may be some of the reasons for the discrepancy between the data reported in the early and recent literature.

In $\mathrm{CF}$ therapy, toxicity issues are complicated by the fact that many CF patients have a history of lifelong treatment with nephrotoxic agents and might show multi-organ damage in advanced disease, putting them at an increased risk of drug side effects. Therefore, it is important to assess toxicity issues in a CF-disease-specific way. The first controlled prospective study on the toxicity of intravenous colistin in $\mathrm{CF}$ was conducted by Conway et al. ${ }^{29} \mathrm{~A}$ total of 53 patients chronically infected with $P$. aeruginosa were treated with intravenous colistin during an acute exacerbation. Only a low incidence of renal impairment, which was always transient, could be observed. In a recent retrospective study following 113 adult $\mathrm{CF}$ patients treated with different nephrotoxic antimicrobial agents including colistin over nearly a decade, the intravenous use of nephrotoxic antibiotics was not found to be associated with major long-term renal toxicity. ${ }^{86}$ Thus, it is necessary to place in perspective the nephrotoxic potential of colistimethate sodium. First, the large amount of evidence 
from studies from the 1990 s onward point out that renal damage due to intravenously administered colistimethate is mild and almost always reversible. Second, colistin is not the only potentially nephrotoxic antibiotic. Interestingly, in studies comparing the nephrotoxicity of intravenous colistin and aminoglycosides in patients with CF, colistin compared favorably with the aminoglycosides. ${ }^{87,88}$

Neurotoxicity (manifested as dizziness, weakness, peripheral paresthesia, vertigo, confusion, ataxia, or neuromuscular blockade) of systemically used colistin is potentially severe but occurs rarely according to the earlier literature: milder symptoms, such as the most frequently reported paresthesias, were reported in up to $27 \%$ of patients..$^{89,90}$ As far as severe neurotoxic symptoms are concerned, at least eight cases were published between 1964 and 1973 correlating the intramuscular administration of polymyxins with the development of episodes of respiratory apnea (reviewed by Falagas et $\mathrm{al}^{24}$ ). However, no episodes of neuromuscular blockade or apnea induced by polymyxins have been reported in the literature in more than 20 years. In the prospective study by Conway et al, neurological symptoms potentially attributable to intravenous colistin treatment were reported in about half of the treatment courses but were - except for in one patient who withdrew from the study because of the symptoms - well tolerated, did not necessitate a reduction in therapy, and resolved shortly after treatment, with no signs of long-term toxicity. ${ }^{29}$ Similarly, in the retrospective study by Bosso et al, ${ }^{91}$ six cases of minor neurological side effects not requiring withdrawal from the study or a reduction in the ongoing therapy were seen in 21 treatment courses. In a review of existing studies, ${ }^{24,92}$ the reported neurotoxic events were very rare, usually mild, and resolved after the discontinuation of therapy, putting the concern related to severe neurotoxic incidents into a different perspective.

In summary, in $\mathrm{CF}$ patients with multiresistant Gramnegative chronic bacterial infections, the achievable clinical benefit has to be weighed against the risk of drug-induced, mild, reversible kidney injury or transient neurological symptoms. However, renal function and clinical state should be monitored during treatment.

\section{Nontoxic side effects of colistimethate sodium}

Aerosolized antibiotic therapy has the advantage of reducing or avoiding systemic side effects due to negligible systemic bioavailability. However, side effects related to airway reactivity are a frequent problem in aerosol therapy, and have been reported after the inhalation of colistin solution ${ }^{93-95}$ and tobramycin inhalation solution. ${ }^{39,96,97}$ In the study, by Hodson et al, ${ }^{42}$ nebulized colistin and tobramycin caused comparable respiratory side effects such as short-term FEV1 decline and cough directly after inhalation and pharyngitis in $35 \%$ to $49 \%$ of treated patients with no significant difference between the two agents.

With forthcoming dry-powder inhalation techniques, respiratory side effects directly associated with the inhalation procedure became even more relevant. In the Freedom study, which compared colistin dry powder with tobramycin inhalation solution, adverse events such as cough, throat irritation, and abnormal taste were significantly more prevalent in the colistin dry-powder treatment group. ${ }^{45}$ Also, in the EAGER study, dry-powder tobramycin resulted in a significantly higher rate of drug-related cough than the tobramycin solution preparation. ${ }^{46}$ However, optimizing the inhalation technique (inhaling with a constant flow that is not too high) can greatly reduce these side effects.

In the literature, one death was reported after the inhalation of compounded colistimethate due to fatal acute respiratory distress syndrome (ARDS). ${ }^{98}$ This fatal event was probably due to the inhalation of a high concentration of the active colistin base resulting in a massive inflammatory response, because the reconstitution of colistimethate had been carried out long before inhalational use in that case. This event emphasizes the risks associated with the use of agents via a different route of application than those they are licensed for.

\section{Role of colistin in chronic infection with bacteria other than $P$. aeruginosa}

Colistin is active mainly against Gram-negative organisms and is well known for its excellent antibacterial activity against $P$. aeruginosa. In addition, E. coli, Enterobacter spp., Salmonella, Shigella, Klebsiella spp., and A. baumannii are usually susceptible to colistin, whereas Burkholderia spp., Serratia, and Proteus spp. are resistant. ${ }^{19}$ S. aureus, $H$. influenza, and P. aeruginosa are the pathogens isolated most frequently from the airways of CF patients, ${ }^{99}$ but other strains with clinical impact found in CF patients include S. maltophilia, A. xylosoxidans, and Burkholderia spp., ${ }^{2,100}$ of which the latter is associated with a markedly shortened median survival. ${ }^{101}$

For the treatment of $S$. maltophilia, trimethoprim/ sulfamethoxazole is often considered the drug of choice. However, resistance to this agent has been increasingly described. ${ }^{102}$ In an in vitro susceptibility study with S. maltophilia strains isolated from CF patients, ${ }^{103}$ the most 
effective antibiotic tested alone against planktonic and biofilm-grown S. maltophilia isolates was high-dose levofloxacin, closely followed by high-dose colistin (both in doses usually only achievable by inhalation). Colistin was included in many of the most effective double antibiotic combinations, which achieved higher susceptibility rates than single agents. Another in vitro susceptibility study observed minocycline, co-trimoxazole, and doxycycline as the most active antibiotics, followed by chloramphenicol, levofloxacin, and colistin, and, among the combinations with synergistic activity, were ticarcillin/clavulanate plus aztreonam, ticarcillin/clavulanate plus colistin, and ticarcillin/clavulanate plus levofloxacin. ${ }^{104}$ In a further study, doxycycline was the most active agent, way in front of trimethoprim/sulfamethoxazole. ${ }^{105}$ Here, high concentrations of colistin proved more active than those of tobramycin. Thus, colistin has a place in treatment of chronic infection with S. maltophilia in CF. However, efficacy studies with clinical outcome measures are still lacking.

For Achromobacter spp., a retrospective study analyzed the effect of different antibiotic treatment regimes on the chance of Achromobacter eradication in $47 \mathrm{CF}$ patients over a period of 11 years. Combination therapies with meropenem, piperacillin/tazobactam, and trimethoprim/ sulfamethoxazole were highly active against chemotherapynaïve Achromobacter strains, and the application of inhaled ceftazidime, colistin, and tobramycin was associated with a significantly longer time until re-colonization with an Achromobacter strain. ${ }^{106}$

For Burkholderia spp., colistin is usually tested resistant, and thus not the substance of choice. Treatment of Burkholderia colonization remains difficult because of its high resistance pattern and the lack of inhaled antimicrobial agents active against these strains. ${ }^{107}$

In sum, there is only some evidence for the use of colistin in the treatment of bacteria other than P. aeruginosa. Controlled prospective trials are missing.

\section{Colistin dosing issues}

There are sparse data on scientifically based dosage regimens for various groups of patients - in particular, people with CF and subsets of critically ill patients with different levels of renal function (see Nation and Li's review ${ }^{108}$ ). This is partly due to the fact that, at the time colistin came into use, proper drug development procedures were not demanded by drug regulatory agencies, and because of the complex pharmacokinetics resulting from the existence of the many colistin compounds generated in vivo. Further, there is no standardized labeling, complicating comparisons between the different pharmaceutical products; ${ }^{81,109,110}$ some product labels express the content of colistimethate sodium in international units (with $\sim 12,500$ IU corresponding to $1 \mathrm{mg}$ of colistimethate sodium), while other products are labeled with "colistin-base activity", referring to the microbiological activity of its active component, even though the material contained in the vials is colistimethate sodium.

Moreover, the recommended dose ranges and maximum daily doses vary significantly according to manufacturer: ${ }^{81,108}$ for products labeled in international units, the manufacturerrecommended daily dose for an adult with normal renal function is equivalent to $240-480 \mathrm{mg}$ of colistimethate sodium; 111 in contrast, for products labeled with "colistin base activity", the manufacturer-recommended adult dose is equivalent to $400-800 \mathrm{mg}$ of colistimethate sodium. ${ }^{112,113}$ The currently available literature supports a colistimethate dose of $8 \mathrm{mg} / \mathrm{kg} /$ day (maximum $480 \mathrm{mg} /$ day) for the intravenous treatment of pulmonary exacerbations secondary to $P$. aeruginosa infection. ${ }^{81}$ This dose is less than what is recommended by the US Food and Drug Administrationapproved and Cystic Fibrosis Foundation dosing guidelines but in agreement with UK Cystic Fibrosis Trust Antibiotic Working Group recommendations. ${ }^{43}$

There is also debate over the optimal dosing intervals of colistimethate administration and its impact on resistance, toxicity, and clinical efficacy. The bactericidal activity of colistin is concentration dependent, but the in vivo pharmacokinetics and -dynamics of colistimethate sodium are complex due to the multitude of in vivo compounds. There is very limited in vivo pharmacokinetics and -dynamics data about intravenously administered colistimethate in $\mathrm{CF}$ patients; ${ }^{114,115}$ hence, the optimal dosing is still unknown.

A similar lack of evidence applies to the optimal dosing of inhaled colistimethate sodium, which is further complicated by the influence of the inhalation drug-delivery system used. Two pharmacokinetics studies exist in CF patients; ${ }^{116,117}$ however, the authors conclude that the low systemic and high local concentrations of colistin support the use of inhaled colistin in $\mathrm{CF}$ patients infected with $P$. aeruginosa.

Even after many years of routine use of colistin, there are no evidence-based guidelines for systemic or inhalation dosages.

\section{Conclusion}

Tobramycin and colistin are the two most frequently used antibiotics for nebulized antibiotic treatment in CF care, and have been joined more recently by aztreonam lysine. 
For chronic pulmonary infection in $\mathrm{CF}$, intravenous colistin has an important role in the treatment of patients colonized with multiresistant bacteria. It is an effective and sufficiently safe agent as far as toxicity is concerned, since the risk of persisting sequelae is rather low and manageable. Therefore, colistimethate sodium is a relevant treatment option for the intravenous treatment of $P$. aeruginosa infection to stabilize lung function or treat exacerbations in patients infected with multiresistant P. aeruginosa and some other Gram-negative strains. However, intravenous colistimethate sodium should be used with care, and always with consideration of renal function.

For $P$. aeruginosa suppressive therapy, colistin inhalation solution has proven efficacy but might be inferior compared with tobramycin treatment. It definitely is a treatment option for patients with multiresistant organisms, those who do not tolerate or do not benefit from tobramycin, and those experiencing deterioration during tobramycin or aztreonam off-cycles. For the latter - namely, combination therapies clinical trials on efficacy and safety are urgently needed. As an inhaled agent, colistin is very safe, since toxicity is negligible due to very small systemic resorption, but usage of intravenous formulations not designed for inhalation may bear some risks. Colistin powder is a new formulation that recently became available. It has been shown non-inferior to inhaled tobramycin. The side effects of colistin dry powder are not different in incidence to those of tobramycin dry powder. Thus, tobramycin and colistin dry powders are two new effective formulations that can be used to provide more ease for patients in long-term P. aeruginosa therapy.

\section{Disclosure}

MB is/has been on advisory boards with Chiesi, Forest Laboratories, Gilead, and Novartis, and has received a travel grant from Gilead. CK-R has received travel grants from Novartis and Forest Laboratories, and was sponsored as a speaker by Gilead. The authors report no other conflicts of interest in this work.

\section{References}

1. Emerson J, Rosenfeld M, McNamara S, Ramsey B, Gibson RL. Pseudomonas aeruginosa and other predictors of mortality and morbidity in young children with cystic fibrosis. Pediatr Pulmonol. 2002;34(2): 91-100.

2. Cystic Fibrosis Foundation. Patient Registry: Annual Data Report 2012. Bethesda, MD: Cystic Fibrosis Foundation; 2013. Available from: http://www.cysticfibrosisdata.org/LiteratureRetrieve.aspx?ID=149756. Accessed May 9, 2014.

3. Proesmans M, Vermeulen F, Boulanger L, Verhaegen J, De Boeck K. Comparison of two treatment regimens for eradication of Pseudomonas aeruginosa infection in children with cystic fibrosis. J Cyst Fibros. 2013;12(1):29-34.
4. Taccetti G, Bianchini E, Cariani L, et al; Italian Group for P aeruginosa Eradication in Cystic Fibrosis. Early antibiotic treatment for Pseudomonas aeruginosa eradication in patients with cystic fibrosis: a randomised multicentre study comparing two different protocols. Thorax. 2012;67(10):853-859.

5. Lillquist YP, Cho E, Davidson AG. Economic effects of an eradication protocol for first appearance of Pseudomonas aeruginosa in cystic fibrosis patients: 1995 vs 2009. J Cyst Fibros. 2011;10(3):175-180.

6. Langton Hewer SC, Smyth AR. Antibiotic strategies for eradicating Pseudomonas aeruginosa in people with cystic fibrosis. Cochrane Database Syst Rev. 2009;7(4):CD004197.

7. Hansen CR, Pressler T, Høiby N. Early aggressive eradication therapy for intermittent Pseudomonas aeruginosa airway colonization in cystic fibrosis patients: 15 years experience. J Cyst Fibros. 2008;7(6): 523-530.

8. Brochet MS, McDuff AC, Bussières JF, et al. Comparative efficacy of two doses of nebulized colistimethate in the eradication of Pseudomonas aeruginosa in children with cystic fibrosis. Can Respir J. 2007;14(8):473-479.

9. Littlewood JM, Koch C, Lambert PA, et al. A ten year review of colomycin. Respir Med. 2000;94(7):632-640.

10. Ramsey BW, Dorkin HL, Eisenberg JD, et al. Efficacy of aerosolized tobramycin in patients with cystic fibrosis. N Engl J Med. 1993;328(24): 1740-1746.

11. Ramsey BW, Pepe MS, Quan JM, et al. Intermittent administration of inhaled tobramycin in patients with cystic fibrosis. Cystic Fibrosis Inhaled Tobramycin Study Group. N Engl J Med. 1999;340(1):23-30.

12. Wiesemann HG, Steinkamp G, Ratjen F, et al. Placebo-controlled, double-blind, randomized study of aerosolized tobramycin for early treatment of Pseudomonas aeruginosa colonization in cystic fibrosis. Pediatr Pulmonol. 1998;25(2):88-95.

13. Steinkamp G, Tümmler B, Malottke R, von der Hardt H. Treatment of pseudomonas aeruginosa colonisation in cystic fibrosis. Arch Dis Child. 1989;64:1022-1028.

14. McCoy KS, Quittner AL, Oermann CM, Gibson RL, Retsch-Bogart GZ, Montgomery AB. Inhaled aztreonam lysine for chronic airway Pseudomonas aeruginosa in cystic fibrosis. Am J Respir Crit Care Med. 2008;178(9):921-928.

15. Retsch-Bogart GZ, Quittner AL, Gibson RL, et al. Efficacy and safety of inhaled aztreonam lysine for airway Pseudomonas in cystic fibrosis. Chest. 2009;135(5):1223-1232.

16. Oermann CM, Retsch-Bogart GZ, Quittner AL, et al. An 18-Month study of the safety and efficacy of repeated courses of inhaled aztreonam lysine in cystic fibrosis. Pediatr Pulmonol. 2010;45(11):1121-1134.

17. Hoffman LR, Ramsey BW. Cystic fibrosis therapeutics. The road ahead. Chest. 2013;143(1):207-213.

18. Dickie KJ, De Groot WJ. Ventilatory effects of aerosolized kanamycin and polymyxin. Chest. 1973;63(5):694-697.

19. Evans ME, Feola DJ, Rapp RP. Polymyxin B sulfate and colistin: old antibiotics for emerging multiresistant gram-negative bacteria. Ann Pharmacother. 1999;33(9):960-967.

20. Rogers MJ, Cohen J. Comparison of the binding of gram-negative bacterial endotoxin by polymyxin B sulphate, colistin sulphate and colistin sulphomethate sodium. Infection. 1986;14(2):79-81.

21. Bozkurt-Güzel C, Gerçeker AA. Post-antibiotic effect of colistin, alone and in combination with amikacin, on Pseudomonas aeruginosa strains isolated from cystic fibrosis patients. J Antibiot (Tokyo). 2012; 65(2):83-86.

22. Gaibani P, Lombardo D, Lewis RE, et al. In vitro activity and postantibiotic effects of colistin in combination with other antimicrobials against colistin-resistant KPC-producing Klebsiella pneumoniae bloodstream isolates. J Antimicrob Chemother. Epub March 19, 2014.

23. Biswas S, Brunel JM, Dubus JC, Reynaud-Gaubert M, Rolain JM. Colistin: an update on the antibiotic of the 21st century. Expert Rev Anti Infect Ther. 2012;10(8):917-934.

24. Falagas ME, Kasiakou SK. Toxicity of polymyxins: a systematic review of the evidence from old and recent studies. Critical Care. 2006; 10(1):R27. 
25. Tumbarello M, De Pascale G, Trecarichi EM, et al. Effect of aerosolized colistin as adjunctive treatment on the outcomes of microbiologically documented ventilator-associated pneumonia caused by colistin-only susceptible gram-negative bacteria. Chest. 2013;144(6):1768-1775.

26. Falagas ME, Rafailidis PI, Ioannidou E, et al. Colistin therapy for microbiologically documented multidrug-resistant Gram-negative bacterial infections: a retrospective cohort study of 258 patients. Int $J$ Antimicrob Agents. 2010;35(2):194-199.

27. Michalopoulos A, Fotakis D, Virtzili S, et al. Aerosolized colistin as adjunctive treatment of ventilator-associated pneumonia due to multidrug-resistant Gram-negative bacteria: a prospective study. Respir Med. 2008;102(3):407-412.

28. Jensen T, Pedersen SS, Garne S, Heilmann C, Høiby N, Koch C. Colistin inhalation therapy in cystic fibrosis patients with chronic Pseudomonas aeruginosa lung infection. J Antimicrob Chemother. 1987;19(6): 831-838.

29. Conway SP, Pond MN, Watson A, Etherington C, Robey HL, Goldman MH. Intravenous colistin sulphomethate in acute respiratory exacerbations in adult patients with cystic fibrosis. Thorax. 1997;52(11):987-993.

30. Mukhopadhyay S, Singh M, Cater JI, Ogston S, Franklin M, Olver RE. Nebulised antipseudomonal antibiotic therapy in cystic fibrosis: a metaanalysis of benefits and risks. Thorax. 1996;51(4):364-368.

31. Touw DJ, Brimcombe RW, Hodson ME, Heijerman HG, Bakker W. Inhalation of antibiotics in cystic fibrosis. Eur Respir J. 1995;8(9): 1594-1604.

32. Conway SP. Nebulized antibiotic therapy: the evidence. Chron Respir Dis. 2005;2(1):35-41

33. Heijerman H, Westerman E, Conway S, Touw D, Döring G; Consensus Working Group. Inhaled medication and inhalation devices for lung disease in patients with cystic fibrosis: A European consensus. $J$ Cyst Fibros. 2009;8(5):295-315.

34. Flume PA, O'Sullivan BP, Robinson KA, et al; Cystic Fibrosis Foundation, Pulmonary Therapies Committee. Cystic fibrosis pulmonary guidelines: chronic medications for maintenance of lung health. Am J Respir Crit Care Med. 2007;176(10):957-969.

35. Döring G, Flume P, Heijerman H, Elborn JS; Consensus Study Group. Treatment of lung infection in patients with cystic fibrosis: current and future strategies. J Cyst Fibros. 2012;11(6):461-479.

36. Littlewood JM, Miller MG, Ghoneim AT, Ramsden CH. Nebulised colomycin for early Pseudomonas colonization in cystic fibrosis. Lancet. 1985;1(8433):865-867.

37. Frederiksen B, Koch C, Høiby N. Antibiotic treatment of initial colonization with Pseudomonas aeruginosa postpones chronic infection and prevents deterioration of pulmonary function in cystic fibrosis. Pediatr Pulmonol. 1997;23(5):330-335.

38. Moss RB. Administration of aerosolized antibiotics in cystic fibrosis patients. Chest. 2001;120(Suppl 3):S107-S113.

39. Moss RB. Long-term benefits of inhaled tobramycin in adolescent patients with cystic fibrosis. Chest. 2002;121(1):55-63.

40. Lenoir G, Antypkin YG, Miano A, et al. Efficacy, safety, and local pharmacokinetics of highly concentrated nebulized tobramycin in patients with cystic fibrosis colonized with Pseudomonas aeruginosa. Pediatr Drugs. 2007;9 Supp1 1:S11-S20.

41. Chuchalin A, Csiszér E, Gyurkovics K, et al. A formulation of aerosolized tobramycin (Bramitob) in the treatment of patients with cystic fibrosis and Pseudomonas aeruginosa infection: a doubleblind, placebo-controlled, multicenter study. Paediatr Drugs. 2007; 9 Suppl 1:S21-S31.

42. Hodson ME, Gallagher CG, Govan JR. A randomised clinical trial of nebulised tobramycin or colistin in cystic fibrosis. Eur Respir J. 2002;20(3):658-664.

43. Cystic Fibrosis Trust. Antibiotic Treatment for Cystic Fibrosis: Report of the UK Cystic Fibrosis Trust Antibiotic Working Group. 3rd ed. Bromley: Cystic Fibrosis Trust; 2009. Available from: http://www.cysticfibrosis. org.uk/media/82010/CD_Antibiotic_treatment_for_CF_May_09.pdf. Accessed May 9, 2014.
44. Adeboyeku D, Scott S, Hodson ME. Open follow-up study of tobramycin nebuliser solution and colistin in patients with cystic fibrosis. $J C y s t$ Fibros. 2006;5(4):261-263.

45. Schuster A, Haliburn C, Döring G, Goldman MH; Freedom Study Group. Safety, efficacy and convenience of colistimethate sodium dry powder for inhalation (Colobreathe DPI) in patients with cystic fibrosis: a randomised study. Thorax. 2013;68(4):344-350.

46. Konstan MW, Flume PA, Kappler M, et al. Safety, efficacy and convenience of tobramycin inhalation powder in cystic fibrosis patients: The EAGER trial. J Cyst Fibros. 2011;10(1):54-61.

47. Konstan MW, Geller DE, Minić P, Brockhaus F, Zhang J, Angyalosi G. Tobramycin inhalation powder for P. aeruginosa infection in cystic fibrosis: The EVOLVE trial. Pediatr Pulmonol. 2011;46(3):230-238.

48. Assael BM, Pressler T, Bilton D, et al; AZLI Active Comparator Study Group. Inhaled aztreonam lysine vs. inhaled tobramycin in cystic fibrosis: A comparative efficacy trial. J Cyst Fibros. 2013;12(2): 130-140.

49. Máiz L, Girón RM, Olveira C, et al. Inhaled antibiotics for the treatment of chronic bronchopulmonary Pseudomonas aeruginosa infection in cystic fibrosis: systematic review of randomised controlled trials. Expert Opin Pharmacother. 2013;14(9):1135-1149.

50. Ryan G, Singh M, Dwan K. Inhaled antibiotics for long-term therapy in cystic fibrosis. Cochrane Database Syst Rev. 2011;(3):CD001021.

51. Littlewood KJ, Higashi K, Jansen JP, et al. A network meta-analysis of the efficacy of inhaled antibiotics for chronic Pseudomonas infections in cystic fibrosis. $J$ Cyst Fibros. 2012;11(5):419-426.

52. Nasr SZ, Sakmar E, Christodoulou E, Eckhardt BP, Streetman DS, Strouse PJ. The use of high resolution computerized tomography (HRCT) of the chest in evaluating the effect of tobramycin solution for inhalation in cystic fibrosis lung disease. Pediatr Pulmonol. 2010;45(5): 440-449.

53. Ballmann M, Smyth A, Geller DE. Therapeutic approaches to chronic cystic fibrosis respiratory infections with available, emerging aerosolized antibiotics. Respir Med. 2011;105 Suppl 2:S2-S8.

54. Pamp SJ, Gjermansen M, Johansen HK, Tolker-Nielsen T. Tolerance to the antimicrobial peptide colistin in Pseudomonas aeruginosa biofilms is linked to metabolically active cells, and depends on the pmr and mexAB-oprM genes. Mol Microbiol. 2008;68(1):223-240.

55. Herrmann G, Yang L, Wu H, et al. Colistin-tobramycin combinations are superior to monotherapy concerning the killing of biofilm Pseudomonas aeruginosa. $J$ Infect Dis. 2010;202(10):1585-1592.

56. VanDevanter DR, Ballmann M, Flume PA. Applying clinical outcome variables to appropriate aerosolized antibiotics for the treatment of patients with cystic fibrosis. Respir Med. 2011;105 Suppl 2: S18-S23.

57. Henwood CJ, Livermore DM, James D, Warner M; Pseudomonas Study Group. Antimicrobial susceptibility of Pseudomonas aeruginosa: results of a UK survey and evaluation of the British Society for Antimicrobial Chemotherapy disc susceptibility test. J Antimicrob Chemother. 2001;47(6):789-799.

58. Michalopoulos AS, Karatza DC. Multidrug-resistant Gramnegative infections: the use of colistin. Expert Rev Anti Infect Ther. 2010;8(9):1009-1017.

59. Li J, Nation RL, Turnidge JD, et al. Colistin: the re-emerging antibiotic for multidrug-resistant Gram-negative bacterial infections. Lancet Infect Dis. 2006;6(9):589-601.

60. Emerson J, McNamara S, Buccat AM, Worrell K, Burns JL. Changes in cystic fibrosis sputum microbiology in the United States between 1995 and 2008. Pediatr Pulmonol. 2010;45(4):363-370.

61. Taccetti G, Campana S, Marianelli L. Multiresistant non-fermentative gram-negative bacteria in cystic fibrosis patients: the results of an Italian multicenter study. Italian Group for Cystic Fibrosis microbiology. Eur J Epidemiol. 1999;15(1):85-88.

62. Ciofu O, Giwercman B, Pedersen SS, Høiby N. Development of antibiotic resistance in Pseudomonas aeruginosa during two decades of antipseudomonal treatment at the Danish CF Center. APMIS. 1994;102(9):674-680. 
63. Pitt TL, Sparrow M, Warner M, Stefanidou M. Survey of resistance of Pseudomonas aeruginosa from UK patients with cystic fibrosis to six commonly prescribed antimicrobial agents. Thorax. 2003;58(9): 794-796.

64. Schülin T. In vitro activity of the aerosolized agents colistin and tobramycin and five intravenous agents against Pseudomonas aeruginosa isolated from cystic fibrosis patients in southwestern Germany. J Antimicrob Chemother. 2002;49(2):403-406.

65. Livermore DM. Multiple mechanisms of antimicrobial resistance in Pseudomonas aeruginosa: our worst nightmare? Clin Infect Dis. 2002;34(5):634-640.

66. Valenza G, Radike K, Schoen C, et al. Resistance to tobramycin and colistin in isolates of Pseudomonas aeruginosa from chronically colonized patients with cystic fibrosis under antimicrobial treatment. Scand J Infect Dis. 2010;42(11-12):885-889.

67. LiPuma JJ. Microbiological and immunologic considerations with aerosolized drug delivery. Chest. 2001;120(Suppl 3):S118-S123.

68. Hurley MN, Ariff AH, Bertenshaw C, Bhatt J, Smyth AR. Results of antibiotic susceptibility testing do not influence clinical outcome in children with cystic fibrosis. J Cyst Fibros. 2012;11(4):288-292.

69. Aaron SD, Vandemheen KL, Ferris W, et al. Combination antibiotic susceptibility testing to treat exacerbations of cystic fibrosis associated with multiresistant bacteria: a randomised, double-blind, controlled clinical trial. Lancet. 2005;366(9484):463-471.

70. Waters V, Ratjen F. Combination antimicrobial susceptibility testing for acute exacerbations in chronic infection of Pseudomonas aeruginosa in cystic fibrosis. Cochrane Database Syst Rev. 2008;(3):CD006961.

71. Sanders DB, Bittner RC, Rosenfeld M, Redding GJ, Goss CH. Pulmonary exacerbations are associated with subsequent FEV1 decline in both adults and children with cystic fibrosis. Pediatr Pulmonol. 2011;46(4):393-400

72. Sanders DB, Bittner RC, Rosenfeld M, Hoffman LR, Redding GJ, Goss $\mathrm{CH}$. Failure to recover to baseline pulmonary function after cystic fibrosis pulmonary exacerbation. Am J Respir Crit Care Med. 2010;182(5):627-632.

73. Parkins MD, Rendall JC, Elborn JS. Incidence and risk factors for pulmonary exacerbation treatment failures in patients with cystic fibrosis chronically infected with Pseudomonas aeruginosa. Chest. 2012;141(2):485-493.

74. Ryan G, Jahnke N, Remmington T. Inhaled antibiotics for pulmonary exacerbations in cystic fibrosis. Cochrane Database Syst Rev. 2012;12:CD008319.

75. Flume PA, Mogayzel PJ Jr, Robinson KA, et al; Clinical Practice Guidelines for Pulmonary Therapies Committee. Cystic fibrosis pulmonary guidelines: treatment of pulmonary exacerbations. Am J Respir Crit Care Med. 2009;180(9):802-808.

76. Gibson RL, Burns JL, Ramsey BW. Pathophysiology and management of pulmonary infections in cystic fibrosis. Am J Respir Crit Care Med. 2003;168(8):918-951.

77. Döring G, Conway SP, Heijerman HG, et al. Antibiotic therapy against Pseudomonas aeruginosa in cystic fibrosis: a European consensus. Eur Respir J. 2000;16(4):749-767.

78. Zobell JT, Young DC, Waters CD, et al. Optimization of antipseudomonal antibiotics for cystic fibrosis pulmonary exacerbations: VI. Executive summary. Pediatr Pulmonol. 2013;48(6):525-537.

79. Ledson MJ, Gallagher MJ, Cowperthwaite C, Convery RP, Walshaw MJ Four years' experience of intravenous colomycin in an adult cystic fibrosis unit. Eur Respir J. 1998;12(3):592-594.

80. Conway SP, Etherington C, Munday J, Goldman MH, Strong JJ, Wootton M. Safety and tolerability of bolus intravenous colistin in acute respiratory exacerbations in adults with cystic fibrosis. Ann Pharmacother. 2000;34(11):1238-1242.

81. Young DC, Zobell JT, Waters CD, et al. Optimization of antiPseudomonal antibiotics for cystic fibrosis pulmonary exacerbations: IV. Colistimethate sodium. Pediatr Pulmonol. 2013;48:1-7.

82. Gounden R, Bamford C, van Zyl-Smit R, Cohen K, Maartens G. Safety and effectiveness of colistin compared with tobramycin for multi-drug resistant Acinetobacter baumannii infections. BMC Infect Dis. 2009;9:26.
83. Kallel H, Hergafi L, Bahloul M, et al. Safety and efficacy of colistin compared with imipenem in the treatment of ventilator-associated pneumonia: a matched case-control study. Intensive Care Med. 2007; 33(7):1162-1167.

84. Koomanachai P, Tiengrim S, Kiratisin P, Thamlikitkul V. Efficacy and safety of colistin (colistimethate sodium) for therapy of infections caused by multidrug-resistant Pseudomonas aeruginosa and Acinetobacter baumannii in Siriraj Hospital, Bangkok, Thailand. Int J Infect Dis. 2007;11(5):402-406.

85. Hartzell JD, Neff R, Ake J, et al. Nephrotoxicity associated with intravenous colistin (colistimethate sodium) treatment at a tertiary care medical center. Clin Infect Dis. 2009;48(12):1724-1728.

86. Florescu MC, Lyden E, Murphy PJ, Florescu DF, Fillaus J. Long-term effect of chronic intravenous and inhaled nephrotoxic antibiotic treatment on the renal function of patients with cystic fibrosis. Hemodial Int. 2012;16(3):414-419.

87. Al-Aloul M, Miller H, Alapati S, Stockton PA, Ledson MJ, Walshaw MJ. Renal impairment in cystic fibrosis patients due to repeated intravenous aminoglycoside use. Pediatr Pulmonol. 2005;39(1):15-20.

88. Etherington C, Bosomworth M, Clifton I, Peckham DG, Conway SP. Measurement of urinary N-acetyl-b-D-glucosaminidase in adult patients with cystic fibrosis: before, during and after treatment with intravenous antibiotics. J Cyst Fibros. 2007;6(1):67-73.

89. Koch-Weser J, Sidel VW, Federman EB, Kanarek P, Finer DC, Eaton AE. Adverse effects of sodium colistimethate. Manifestations and specific reaction rates during 317 courses of therapy. Ann Intern Med. 1970;72(6):857-868.

90. Fekety FR Jr, Norman PS, Cluff LE. The treatment of gram-negative bacillary infections with colistin. The toxicity and efficacy of large doses in forty-eight patients. Ann Intern Med. 1962;57:214-229.

91. Bosso JA, Liptak CA, Seilheimer DK, Harrison GM. Toxicity of colistin in cystic fibrosis patients. DICP. 1991;25(11):1168-1170.

92. Dhariwal AK, Tullu MS. Colistin: re-emergence of the 'forgotten' antimicrobial agent. J Postgrad Med. 2013;59(3):208-215.

93. Maddison J, Dodd M, Webb AK. Nebulized colistin causes chest tightness in adults with cystic fibrosis. Respir Med. 1994;88(2):145-147.

94. Dodd ME, Abbott J, Maddison J, Moorcroft AJ, Webb AK. Effect of tonicity of nebulised colistin on chest tightness and pulmonary function in adults with cystic fibrosis. Thorax. 1997;52(7):656-658.

95. Cunningham S, Prasad A, Collyer L, Carr S, Lynn IB, Wallis C. Bronchoconstriction following nebulised colistin in cystic fibrosis. Arch Dis Child. 2001;84(5):432-433.

96. Alothman GA, Alsaadi MM, Ho BL, et al. Evaluation of bronchial constriction in children with cystic fibrosis after inhaling two different preparations of tobramycin. Chest. 2002;122(3):930-934.

97. Nikolaizik WH, Trociewicz K, Ratjen F. Bronchial reactions to the inhalation of high-dose tobramycin in cystic fibrosis. Eur Respir J. 2002;20(1):122-126.

98. McCoy KS. Compounded colistimethate as possible cause of fatal acute respiratory distress syndrome. $N$ Engl J Med. 2007;357(22): 2310-2311.

99. Govan JR, Glass S. The microbiology and therapy of cystic fibrosis lung infection. Rev Med Microbiol. 1990;1:19-28.

100. Steinkamp G, Wiedemann B, Rietschel E, et al; Emerging Bacteria Study Group. Prospective evaluation of emerging bacteria in cystic fibrosis. J Cyst Fibros. 2005;4(1):41-48.

101. Liou TG, Adler FR, FitzSimmons SC, Cahill BC, Hibbs JR, Marshall BC. Predictive 5-year survivorship model of cystic fibrosis. Am J Epidemiol. 2001;153(4):345-352.

102. Toleman MA, Bennett PM, Bennett DM, Jones RN, Walsh TR. Global emergence of trimethoprim/sulfamethoxazole resistance in Stenotrophomonas maltophilia mediated by acquisition of sul genes. Emerg Infect Dis. 2007;13(4):559-565.

103. Wu K, Yau YC, Matukas L, Waters V. Biofilm compared to conventional antimicrobial susceptibility of Stenotrophomonas maltophilia Isolates from cystic fibrosis patients. Antimicrob Agents Chemother. 2013;57(3):1546-1548. 
104. Milne KE, Gould IM. Combination antimicrobial susceptibility testing of multidrug-resistant Stenotrophomonas maltophilia from cystic fibrosis patients. Antimicrob Agents Chemother. 2012;56(8):4071-4077.

105. San Gabriel P, Zhou J, Tabibi S, Chen Y, Trauzzi M, Saiman L. Antimicrobial susceptibility and synergy studies of Stenotrophomonas maltophilia isolates from patients with cystic fibrosis. Antimicrob Agents Chemother. 2004;48(1):168-171.

106. Wang M, Ridderberg W, Hansen CR, et al. Early treatment with inhaled antibiotics postpones next occurrence of Achromobacter in cystic fibrosis. J Cyst Fibros. 2013;12(6):638-643.

107. Tullis DE, Burns JL, Retsch-Bogart GZ, et al. Inhaled aztreonam for chronic Burkholderia infection in cystic fibrosis: a placebo-controlled trial. J Cyst Fibros. 2014;13(3):269-305.

108. Nation RL, Li J. Colistin in the 21 st Century. Curr Opin Infect Dis. 2009;22(6):535-543.

109. Li J, Nation RL, Turnidge JD. Defining the dosage units for Colistin Methanesulfonate: urgent need for international harmonization. Antimicrob Agents Therapy. 2006;50(12):4231-4232.

110. Payne DJ1, Gwynn MN, Holmes DJ, Pompliano DL. Drugs for bad bugs: confronting the challenges of antibacterial discovery. Nat Rev Drug Discov. 2007;6(1):29-40.
111. Colomycin Injection [product information]. Forest Laboratories UK Ltd; 2010.

112. Colistimethate for Injection [product information]. X-Gen Pharmaceuticals; 2010.

113. Colo-Mycin ${ }^{\circledR}$ M Parenteral [product information]. Parkedale Pharmaceuticals, Inc; 2006

114. Reed MD, Stern RC, O'Riordan MA, Blumer JL. The pharmacokinetics of colistin in patients with cystic fibrosis. J Clin Pharmacol. 2001;41(6):645-654.

115. Li J, Coulthard K, Milne R, et al. Steady-state pharmacokinetics of intravenous colistin methanesulphonate in patients with cystic fibrosis. J Antimicrob Chemother. 2003;52(6):987-992.

116. Ratjen F, Rietschel E, Kasel D, et al. Pharmacokinetics of inhaled colistin in patients with cystic fibrosis. J Antimicrob Chemother. 2006;57(2):306-311.

117. Byrne NM, Keavey PM, Perry JD, Gould FK, Spencer DA. Comparison of lung deposition of colomycin using the HaloLite and the Pari LC Plus nebulisers in patients with cystic fibrosis. Arch Dis Child. 2003;88(8):715-718.
Core Evidence

\section{Publish your work in this journal}

Core Evidence is an international, peer-reviewed open-access journal evaluating the evidence underlying the potential place in therapy of drugs throughout their development lifecycle from preclinical to postlaunch. The focus of each review is to evaluate the case for a new drug or class in outcome terms in specific indications and patient groups.

\section{Dovepress}

The manuscript management system is completely online and includes a very quick and fair peer-review system, which is all easy to use. Visit http://www.dovepress.com/testimonials.php to read real quotes from published authors. 